\title{
Alteration of the Optical and Mechanical Characteristics of Cellulose Nanofibre Films Under Thermal Treatment
}

Ilpo Niskanen ( $\boldsymbol{D}$ ilpo.niskanen@oulu.fi )

Univeristy of Oulu https://orcid.org/0000-0002-9940-6072

Kaitao Zhang

University of Oulu: Oulun Yliopisto

Henrikki Liimatainen

University of Oulu: Oulun Yliopisto

Shuhei Shibata

Utsunomiya Daigaku

Nathan Hagen

Utsunomiya Daigaku

Rauno Heikkilä

University of Oulu: Oulun Yliopisto

Hidehiko Yoda

Utsunomiya Daigaku

Yukitoshi Otani

Utsunomiya Daigaku

\section{Research Article}

Keywords: Nanocellulose, thermal treatment, complex refractive index, birefringence, mechanical properties, thermal stability

Posted Date: June 18th, 2021

DOl: https://doi.org/10.21203/rs.3.rs-589761/v1

License: (c) (i) This work is licensed under a Creative Commons Attribution 4.0 International License.

Read Full License 
1 Alteration of the optical and mechanical

2 characteristics of cellulose nanofibre films

3 under thermal treatment

4 Ilpo Niskanen ${ }^{\mathrm{a}}$, Kaitao Zhang ${ }^{\mathrm{b}}$, Henrikki Liimatainen ${ }^{\mathrm{b}}$, Shuhei Shibatac ${ }^{\mathrm{c}}$, Nathan Hagenc,

5 Rauno Heikkiläa, Hidehiko Yoda ${ }^{d}$, Yukitoshi Otani ${ }^{c}$

$6 \quad{ }^{a}$ Faculty of Technology, Structures and Construction Technology, University of

7 Oulu, P.O. Box 7300, FI-90014 Oulu, Finland

$8 \quad{ }^{b}$ Faculty of Technology, Fibre and Particle Engineering, University of Oulu, P.O.

9 Box 4300, FI-90014, Oulu, Finland

10 ' Optical Information Processing and Systems Engineering Division, The Graduate School

11 for the Creation of New Photonics Industries, 1955-1, Kurematsucho, Nishi-ku,

12 Hamamatsu-shi, Shizuoka-ken, 431-1202, Japan

$13{ }^{\mathrm{d}}$ Graduate School of Engineering, Utsunomiya University, 7-1-2 Yoto,

14 Utsunomiya, Tochigi 321-8585, Japan

*) Corresponding author: Ilpo.Niskanen@oulu.fi

Tel: +358443275850

ORCID: 0000-0002-9940-6072

\section{Abstract}

Nanocelluloses and their different designs, such as films and nanopapers, have gained considerable interest in many application areas due to their unique properties. For many purposes, such as for packaging and electronics, the thermal stability of nanocellulose materials is a crucial characteristic. In this study, the effects of heat treatment (100ㄷ, $150^{\circ} \mathrm{C}$ and $\left.200^{\circ} \mathrm{C}\right)$ on the optical and mechanical properties of 2,2,6,6-tetramethylpiperidinyl-1-oxy radical-oxidised cellulose nanofibre (TO-CNF) films were investigated, especially the alteration of the colour, complex refractive index and birefringence of the films. Exposing TO-CNF films to high temperatures (> $150^{\circ} \mathrm{C}$ ) induced permanent transformations in the CNF structure, leading to an increase in the refractive index, decreases in the birefringence and crystallinity index, colour darkening and significant deterioration of the mechanical properties.

Keywords: Nanocellulose; thermal treatment; complex refractive index; birefringence; 


\section{Introduction}

33 Nanocellulose is a functionalisable renewable biopolymer material that has gained

34 increasing interest for a range of applications relevant to the fields of packaging,

35 technical films and foams, nanocomposites, electronics, photonics, medicines, etc.

36 (Abitbol et al. 2016) and Wang et al. 2019). In the last years, several new

37 biorefinery concepts have been established to produce cellulose nanomaterials at a

38 larger scale, and the nanocellulose market is expected to grow from US\$297 million

39 in 2020 to US\$783 million in 2025 (Nanocellulose market, 2020). This trend is

40 promoted by the emerging green circular economy based on renewable resources,

41 and by the unique features of nanocellulose, such as its superior mechanical

42 properties, light weight, high surface area, optical transparency, low coefficient of

43 thermal expansion and tailorable chemistry (Pakharenko et al 2021, Gan et al.

44 2021).

45 The thermal stability and alteration of the nanocellulose characteristics under high

46 temperatures are relevant for many applications, such as packaging, composites and

47 electronics (Agustin et al. 2016). High temperatures $\left(>100^{\circ} \mathrm{C}\right)$ can cause changes

48 in the cellulose molecular and crystal structure and can compact the networked

49 structure of cellulose nano-entities. Controlled thermal treatments of solid

50 nanocellulose materials such as films can also be used to improve the mechanical

51 strength (e.g. tensile strength, elongation at break, Young's modulus) (Rubentheren

52 et al. 2016), reduce the water content reduction (Rubentheren et al. 2016) and

53 increase the hardness (Wu et al. 2013) of the films. Typically, the maximum thermal

54 treatment temperature of nanocelluloses is below $200^{\circ} \mathrm{C}$ because higher

55 temperatures of $200-300^{\circ} \mathrm{C}$ start to degrade the cellulose polymeric structure (Gan

56 et al. 2021). 
57 The optical properties of nanocellulose are important parameters for films and nanopapers, and they may also be affected by elevated temperatures (thermal stress)

59 (Pakharenko et al 2021). The optical properties of nanocellulose films have been commonly investigated by analysing the reflection, absorption, scattering or

61 polarisation of light to obtain different variables, such as transmittance (Sun et al.

$62 \underline{2018)}$, complex refractive index (Niskanen et al. 2019b), optical activity (Zlenko et

63 al. 2019), colour (Vardanyan et al. 2015), birefringence (Orellana et al. 2018),

64 opacity (Zhu et al. 2011), and gloss (Kong et al. 2019). The knowledge of the transformation of the optical characteristics of nanocellulose materials as a function of temperature is still incomplete, and the previous studies have mainly addressed

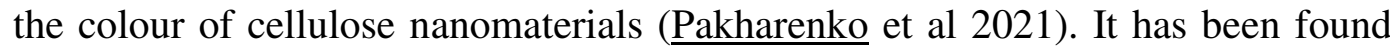
that the values of the colour differences and transmittance increase, and the value of lightness decreases, as a function of the heat treatment temperature. The thermal discolouration has been strongly attributed to the carbonyl and carboxyl functional groups of pure (lining- and hemicellulose-free) cellulose, which can initiate the formation of chromophores especially in the oxidised cellulose nanomaterials such as TEMPO (2,2,6,6-tetramethylpiperidinyl-1-oxy radical) mediated (Ahn et al. 2019).

In our previous work, we developed a method of determining the complex refractive index of cellulose nanocrystals (CNCs) as a function of wavelength by combining the Beer-Lambert and immersion-matching methods (Niskanen et al. 2019b). The sizes of nanocelluloses (CNCs and CNFs) were in turn analysed using Rayleigh approximation and the Mie theory (Niskanen et al. 2019a). The change in the birefringence properties of the thermally modified wood was obtained by measuring the light reflection with a Stokes imaging polarimeter based on the Mueller matrix method (Niskanen et al. 2020). The present study aimed to 
83 investigate the optical (colour, complex refractive index and birefringence),

84 structure (degree of crystallinity, thermal stability and chemical bonds) and

85 mechanical (tensile strength, strain and Young's modulus) properties of heattreated films of 2,2,6,6-tetramethylpiperidinyl-1-oxy radical-oxidised cellulose nanofibres (TO-CNFs) and to provide a further understanding of the behaviour of nanocellulose films at elevated temperatures $\left(100-200^{\circ} \mathrm{C}\right)$.

\section{Materials and Methods}

\section{Materials}

Bleached birch (Betula pendula) chemical wood pulp obtained in dry sheets was used as a cellulose raw material after disintegration in deionised water. The properties of birch pulp were determined in a previous study (Liimatainen et al. 2011). The cellulose, xylan and glukomannan contents of the pulp were $74.8 \%$, $23.6 \%$ and $1.1 \%$, respectively. The 2,2,6,6-tetramethylpiperidinyl-1-oxy radical (TEMPO), sodium bromide and sodium hypochlorite solution $(\mathrm{NaClO}, 15 \mathrm{wt} \%)$ were obtained from Sigma-Aldrich (Finland).

\section{Preparation of TEMPO-oxidised CNFs (TO-CNFs)}

The cellulose pulp was subjected to TEMPO-mediated oxidation, mechanical delamination treatment and purification. The TEMPO-mediated oxidation was performed as previously described [26]. In the present study, $10 \mathrm{mmol} \mathrm{NaClO}$ per gram of pulp fibre was used to achieve a charge density of $1.0 \mathrm{mmol} / \mathrm{g}$. After the oxidation and washing with water (until the conductivity of the filtrate was already below $20 \mu \mathrm{S} / \mathrm{cm}$ ), a suspension with a $0.6 \%$ dry-matter content was prepared and was delaminated via probe sonication for $1 \mathrm{~h}$ (Heilscher UP 400s, $0.5 \mathrm{~s}$ power discharge and $0.5 \mathrm{~s}$ pause, $60 \%$ amplitude and $22 \mathrm{~mm}$ probe tip diameter) to obtain 
108 TO-CNFs. To remove the larger fibres and metal dust generated from the sonication 109 probe and to obtain an aqueous TO-CNF suspension, the sample was centrifuged at $1108,000 \mathrm{rpm}$ for $10 \mathrm{~min}$.

\section{Preparation of TO-CNF films}

112 TO-CNF films were prepared via casting. The TO-CNF suspension was degassed 113 overnight using vacuum and was then poured into a polystyrene Petri dish and dried 114 with $50 \%$ humidity at room temperature for more than 1 week. The obtained self115 standing TO-CNF films were heat-treated in an oven for $3 \mathrm{~h}$ at $100^{\circ} \mathrm{C}, 150^{\circ} \mathrm{C}$ and $116200^{\circ} \mathrm{C}$, respectively. The thicknesses of the TO-CNF films (reference non-treated

117 TO-CNF film and TO-CNF films heat-treated at $100^{\circ} \mathrm{C}, 150^{\circ} \mathrm{C}$ and $200^{\circ} \mathrm{C}$, 118 respectively) measured via scanning electron microscopy were 27.7, 28.2, 27.6 and $11928.1 \mu \mathrm{m}$, respectively.

\section{Characterisation of the TO-CNF films}

121 Colorimeter

122 The colour of the TO-CNF films was measured with a spectrophotometer 123 (Lorentzen \& Wettre Elrepho 070) under a D65 light source. The colour analysis 124 was based on the CIE $1976 \mathrm{~L} * \mathrm{a} * \mathrm{~b} *$ (CIELAB) colour space. The colour was 125 defined by the parameters $\mathrm{L}^{*}=$ lightness (or clarity) of the colour $\left(\mathrm{L}^{*}=0\right.$ yields 126 black and $\mathrm{L}^{*}=100$ white), $\mathrm{a}^{*}=$ position between magenta and green (green 127 indicates negative values and magenta positive) and $b^{*}=$ position between yellow 128 and blue (blue indicates negative values and yellow positive). The colour difference $129 \Delta \mathrm{E}$ between two colour stimuli was calculated as the Euclidean distance between 130 the points representing them in the $\mathrm{L}^{*} \mathrm{a}^{*} \mathrm{~b}^{*}$ colour space (Pakharenko et al 2021; 131 Matsuo et al. 2012). The values of $\Delta \mathrm{E}$ between 0.5 and 1 in colour difference can 132 already be perceived by the human eye. The total colour differences $\Delta E_{-} a b^{\wedge} *$ were 
calculated using the following formulas:

$$
\Delta E_{a b}^{*}=\sqrt{\Delta L^{* 2}+\Delta a^{* 2}+\Delta b^{* 2}}
$$

136 where $\Delta L^{*}=L^{*}-L_{0}^{*}, \Delta a^{*}=a^{*}-a_{0}^{*}$ and $\Delta b^{*}=b^{*}-b_{0}^{*} . L^{*}$ is a lightness, and

$137 a^{*}$ and $b^{*}$ are colour coordinates under the testing conditions. $L_{0}$ is the reference 138 value of the lightness and $a_{0}$ and $b_{0}$ are the reference values of the colour 139 coordinates, respectively.

\section{Spectroscopic photometry}

141 The optical properties of any material can be described by the complex refractive 142 index,

$$
N(\lambda)=n(\lambda)-i k(\lambda)
$$

144 where $\lambda$ is the wavelength, $k$ is the extinction coefficient and $n$ is the real refractive 145 index. The refractive index is defined as the speed of light in a vacuum divided by 146 the speed in the medium. The extinction coefficient (imaginary part) is therefore 147 described as the reciprocal damping of the oscillation amplitude of the incident 148 electric field in the medium (Jackson 1998). The complex refractive index was 149 determined as the absolute (400-1,000 nm) unpolarised reflectance R_0 $(\lambda)$ and 150 transmission T_0 $(\lambda)$ spectrally resolved from the TO-CNF films using a Jasco V151670 with an ARMN-735 absolute-reflectance measurement accessory, at a $5^{\circ}$ angle 152 of incidence. In mathematical form, this is expressed as

$$
R_{0}=\frac{\left(n_{0}-n_{S}\right)^{2}+k^{2}}{\left(n_{0}+n_{S}\right)^{2}+k^{2}}
$$

154 and

$$
T_{0}=\frac{4 \sqrt{n_{s}^{2}+k^{2}}}{\left(1+n_{s}\right)^{2}+k^{2}}
$$

156 where $n_{0}$ is the refractive index of the medium, $n_{\mathrm{s}}$ is the refractive index of the film 
157 and $\kappa$ is the extinction coefficient of the film. Generalising this result to the bulk

158 sample polarised reflectance and transmittance $R_{-} S$ and $T_{-} S$ can be defined as 159 shown below

$$
R_{S}=R_{0}+\frac{T_{0}^{2} R_{0} T_{v}^{2}}{1-R_{0}^{2} T_{v}^{2}}
$$

161 and

$$
T_{S}=\frac{T_{0}^{2} T_{v}}{1-R_{o}^{2} T_{v}^{2}}
$$

where $T_{\mathrm{v}}$ is the transmittance through the volume. Then $T_{\mathrm{v}}$ can be expressed as

$$
T_{v}=\exp (-4 k d / \lambda)
$$

165 where $d$ is the thickness of the film. Using the spectrally resolved bulk sample 166 reflectance and transmission, we estimated the $(n, k)$ model parameters as a function

167 of the wavelength using least-squares fitting to solve the complex refractive index 168 of the film (Macleod 2021; Nilsson 1968).

\section{Polarimeter}

171 The retardance $(\delta)$ is a measure of the phase shifts when linearly polarised

172 components of light pass through a material. The linear retardance of the TO-CNF

173 films in this study was determined using an Axoscan Mueller matrix polarimeter

174 (Axometrics, USA). The spectra (400-800 nm) were measured at $1.0 \mathrm{~nm}$ intervals.

175 The polarisation properties of the TO-CNF films were obtained from the 176 decomposition analysis of the Muller matrix measured by a dual-rotating retarder 177 system, and the polarisation property images were obtained by moving the sample 178 through an XY motor stage (range: 200x200 mm; resolution: $1 \mathrm{~mm}$ ). The 179 birefringence $(\Delta n)$ optically anisotropic film is obtained from the expression 


$$
\Delta n\left(\mathrm{n}_{o}-\mathrm{n}_{e}\right)=(\delta \cdot \lambda) /((2 \pi \cdot d)),
$$

181 where $\delta$ is the retardance, $\lambda$ is the wavelength, $n_{\mathrm{o}}$ is the ordinary refractive index, $n_{\mathrm{e}}$

182 is the extraordinary refractive index and $d$ is the film thickness (Smith 2002).

\section{Transmission electron microscopy (TEM)}

185 The morphological features of TEMPO oxidized CNFs (TO-CNFs) were observed 186 by transmission electron microscope (TEM, JEOL JEM-2200FS, Japan).

187 Preparation of the samples was performed by first adding a small droplet of 0.003 188 to $0.005 \mathrm{wt} \%$ nanocellulose suspension on the top of carbon-coated copper grid. 189 After setting for one minute, the sample was absorbed by a small piece of filter 190 paper, the sample left on the grid was negatively stained with uranyl acetate (2\% $191 \mathrm{w} / \mathrm{v}$ ) for $1 \mathrm{~min}$. The staining agent was then removed again by filter paper. The 192 standard conditions with $200 \mathrm{kV}$ were used during the TEM analysis.

193 Field emission scanning electron microscopy (FESEM)

194 The FESEM images of the films were obtained using a field emission scanning 195 electron microscope (Zeiss Sigma HD VP, Oberkochen, Germany) at a $0.5 \mathrm{kV}$ 196 acceleration voltage. All the samples were sputtered with platinum before 197 observation.

199 The XRD patterns of the samples were recorded using a Rigaku SmartLab $9 \mathrm{~kW}$ 200 XRD machine. The analysis involved the following parameters: $K \alpha$ radiation $\left(K_{\alpha 1}\right.$ $\left.201=1.78892 \AA ; K_{\alpha 2}=1.79278 \AA ; K_{\alpha 1} / K_{\alpha 2}=0.5\right)$ and a scan rate of $3 \%$ min between $20210^{\circ}$ and $50^{\circ} 2 \theta$ and $0.02^{\circ} /$ step size. The crystallinity index $\left(C_{\mathrm{rI}}, \%\right)$ was calculated 203 as shown below.

$$
C_{r I}(\%)=\frac{I_{200}-I_{a m}}{I_{200}} 100,
$$


where $I_{200}$ is the maximum intensity of the principal peak and $I_{\mathrm{am}}$ is the intensity of

206 the diffraction attributed to non-crystalline cellulose.

Diffuse reflectance infrared Fourier transform (DRIFT) spectroscopy

209 Chemical characterisation of the films was carried out using DRIFT spectroscopy.

210 The spectra were recorded on a Bruker Vertex 80v spectrometer (USA) in the 800$2114,000 \mathrm{~cm}^{-1}$ range with a $2 \mathrm{~cm}^{-1}$ resolution.

\section{Thermogravimetric analysis (TGA)}

213 TGA was performed using a thermal analyser (TA Instruments SDT 2960) under

214 nitrogen flow with a constant rate of $60 \mathrm{~mL} \mathrm{~min}^{-1}$. Each measurement was

215 conducted from 30 to $1,000^{\circ} \mathrm{C}$ at a scanning rate of $10 \mathrm{~K} / \mathrm{min}$.

\section{Mechanical properties}

217 The mechanical properties (tensile strength, elongation at break and Young's 218 modulus) of the TO-CNF films were determined using a universal testing machine 219 (Zwick D0724587, Switzerland) equipped with a $1 \mathrm{kN}$ load cell. The Young's 220 modulus was obtained by determining the slope of the tensile strength-strain 221 curves. All the samples were cut into 5-mm-wide strips and were placed at $23 \pm$ $2221{ }^{\circ} \mathrm{C}$ with a relative humidity of $50 \pm 2 \%$ for at least $24 \mathrm{~h}$. The thickness of each 223 specimen was determined using a precision thickness gauge (Hanatek, FT3, St. 224 Leonards-on-Sea, UK), with the average value obtained from three random 225 locations on the sample strip. For the TO-CNF film heat-treated at $200^{\circ} \mathrm{C}$, the 226 average thickness of the film before heat treatment was chosen because of the small

227 bubbles that were found on the film surface after $200^{\circ} \mathrm{C}$ heating. The initial grip 228 separation of the machine was set at $20 \mathrm{~mm}$, and the specimens were tested at a 229 constant crosshead speed of $5 \mathrm{~mm} / \mathrm{min}$. At least five specimens were tested, and the 


\section{Results}

233 Colour changes in the thermally modified TO-CNF films

234 Fig. 1 presents the original, untreated TO-CNF film (reference) and the films heat235 treated at $100^{\circ} \mathrm{C}, 150^{\circ} \mathrm{C}$ and $200^{\circ} \mathrm{C}$, respectively, in an oven.

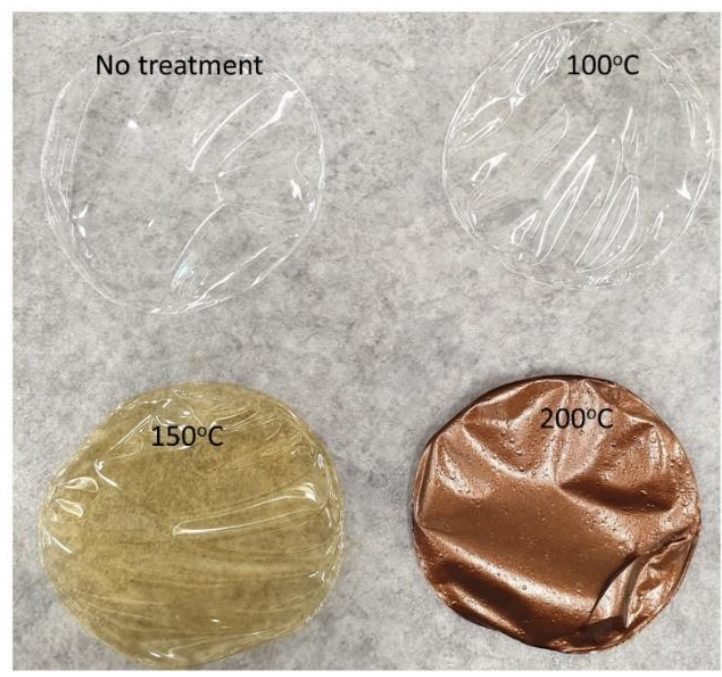

237 Fig. 1. Reference and heat-treated TO-CNF films $\left(100,150,200^{\circ} \mathrm{C}\right)$ with $3 \mathrm{~h}$ 238 treatment time.

240 The alteration of the visual appearance of the films heat-treated at 150 and $200^{\circ} \mathrm{C}$ 241 was clearly perceived with the naked eye, and the colour of the films changed from 242 transparent to light brown as the heat treatment temperature increased. The yellow 243 or brown film discolouration provided a near-complete UV-blocking ability (Yang 244 et al. 2019). Fig. 2 shows the changes in the total colour difference $\left(\Delta \mathrm{E}^{*}\right)$ of the 245 films. The $\Delta \mathrm{E}^{*}$ values of the samples heat-treated for $3 \mathrm{~h}$ at $100^{\circ} \mathrm{C}, 150^{\circ} \mathrm{C}$ and $200^{\circ} \mathrm{C}$ 246 were $1.6,37.8$ and 69.4 , respectively; that is, the $\Delta \mathrm{E}^{*}$ value showed a nonlinear 
247 dependence of the heat treatment temperature, and indicated only minor changes 248 below $100^{\circ} \mathrm{C}$, but notable discolouration was observed at above $150^{\circ} \mathrm{C}$.

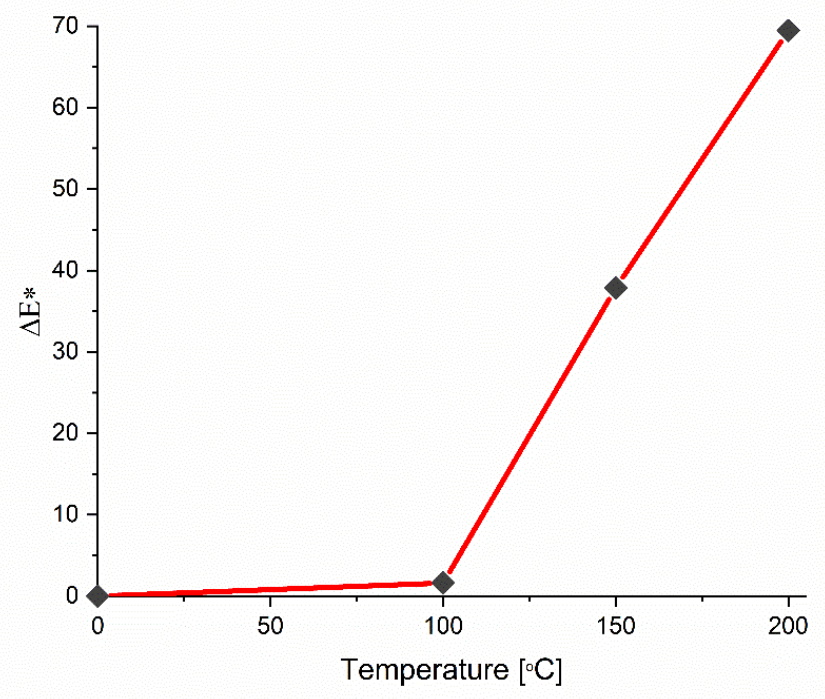

250 Fig. 2. Changes in total colour difference $\left(\Delta \mathrm{E}^{*}\right)$ of the reference and heat-treated 251 TO-CNF films as a function of treatment temperature.

253 Previously, thin CNF films produced using only mechanical treatment had $\Delta \mathrm{E}^{*}$ 254 values of $6.1,6.6,7.3$ and 10.5 at $80^{\circ} \mathrm{C}, 120^{\circ} \mathrm{C}, 160^{\circ} \mathrm{C}$ and $190^{\circ} \mathrm{C}$ (calculated from 255 the figure), respectively (Pakharenko et al. 2021). Therefore, the TO-CNFs in the 256 current work (charge density: $1.0 \mathrm{mmol} / \mathrm{g}$ ) were significantly more prone to thermal 257 discolouration. The oxidised groups in cellulose (i.e. $\mathrm{CO}$ and $\mathrm{COOH}$ ) have been 258 generally noted to promote yellowing. In particular, carbonyl groups initiate the 259 formation of chromophores, which are formed later, upon yellowing. Carboxyl 260 groups in turn have a strong synergetic role when carbonyl groups are present, and 261 they promote acidic catalysis and additional activation by electronic effects (Ahn et 262 al. 2019). Especially, the C2 and C3 ketones and aldehyde groups that can be 263 formed due to side reactions have been previously reported to cause brown 264 discolouration for the TEMPO-oxidised nanocellulose (Isogai et al. 2010). 


\section{Complex refractive index of the thermally modified TO-CNF films}

The influence of heat treatment on the complex refractive index of the TO-

267 CNF films as a function of wavelength is shown in Fig. 3. Fig 3a presents the real 268 effective refractive index spectra of the film samples. The refractive index of 269 untreated CNF had not been previously reported as a function of wavelength; only 270 the value of a single $785 \mathrm{~nm}$ wavelength was available, giving a refractive index of 2711.458 (Reid et al. 2016). The refractive index estimate obtained by our method 272 was $n_{785}=1.454$, matching the literature value very well.

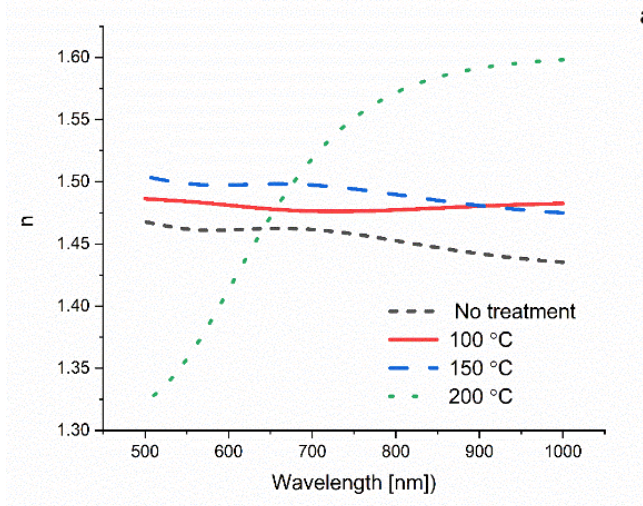

a)

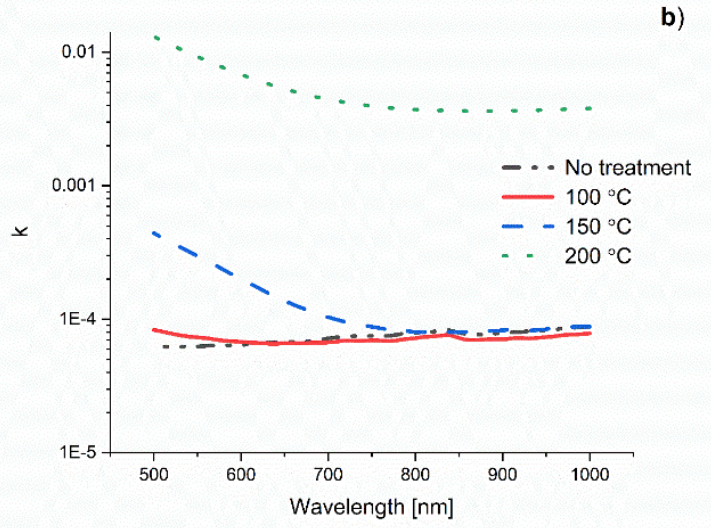

277 Fig. 3. Real (a) and imaginary (b) parts of the complex refractive indices of the reference and heat-treated TO-CNF films. 

decreased or stayed at a constant level as a function of the wavelength of light, except that of the film heat-treated at $200^{\circ} \mathrm{C}$ (Fig. 3a). This behaviour is attributed to the absorption of the Vis part of incident light for the dark film interface. Hence,

284 in such a case, the light reflection usually becomes weak. The effective refractive 285 indices of the thermally modified TO-CNF films increased as a function of the 286 treatment temperature (Fig 3a). According to these results, the values of the 287 ordinary refractive indices increased with a decrement in the extraordinary 288 refractive index values as the temperature increased.

289 The same phenomenon was observed earlier for heat-treated pinewood 290 (Niskanen et al. 2012). The refractive indices of original Scots pine and thermally 291 modified wood treated at $180^{\circ} \mathrm{C}, 200^{\circ} \mathrm{C}$ and $230^{\circ} \mathrm{C}$ were $1.553,1.557,1.587$ and 2921.596 at $589 \mathrm{~nm}$, respectively, as obtained using the liquid immersion technique. 293 The refractive index of Scots pine treated at $230^{\circ} \mathrm{C}$ approached the maximum 294 ordinary refractive index of cellulose (i.e. 1.596 at $589 \mathrm{~nm}$ ). Similarly, the highest 295 heat treatment $\left(200^{\circ} \mathrm{C}\right)$ of the TO-CNF film resulted in a refractive index of 1.598 296 at $1,000 \mathrm{~nm}$. The behaviour of the imaginary part of the complex refractive index curves 298 is shown in Fig. $3 b$ as a function of the wavelength. Significant values of the 299 imaginary part of the complex refractive index were observed only at the higher 300 heat treatment temperatures $\left(150^{\circ} \mathrm{C}\right.$ and $\left.200^{\circ} \mathrm{C}\right)$. The reference (untreated) film and 301 the film heat-treated at $100^{\circ} \mathrm{C}$ had the imaginary part of the refractive index of about 3020.0001 , without large wavelength dependence. For films, extinction coefficients 303 below 0.0001 are generally considered negligible, and low values of the imaginary 304 component of the complex refractive index correspond to high optical transparency. 
306 Birefringence of the thermally modified TO-CNF films

307 Fig. 4 shows the spectral dispersion curves of linear retardance and birefringence $308(\Delta \mathrm{n})$ obtained using optical anisotropy. The birefringence decreased with increasing 309 heat treatment temperatures. The birefringence of optically anisotropic materials 310 such as cellulose is considered a measure of the relative area occupied by non311 crystalline and crystalline regions (Uetani et al. 2019). The decreasing birefringence 312 with the increase in heat treatment temperature indicating that the birefringence has 313 disappeared. As a result, the structure of CNF has been started to degrade. This 314 influences the mechanical properties of the CNF (Manaf et al. 2016). The 315 birefringence provides information about the whole molecular structure of cellulose 316 whereas XRD mainly provides orientation information about the crystals (Uetani et 317 al. 2019). The birefringence of cellulose measured from bacterial CNF films was 318 previously reported to range from 0.047 to 0.090 (Uetani et al. 2019) depending on 319 the differences in the treatment, state of purity, source, wavelength, measurement 320 temperature and measurement method used. In the present study, the level of 321 birefringence was slightly lower and decreased from approx. 0.035 (reference) to 3220.075 at the highest heat treatment temperature. Degushi et al. investigated the 323 birefringence of the water suspension of cellulose fibres using an ellipsometer 324 (Degushi et al. 2006). They observed that the birefringence of cellulose is 325 completely lost at $330^{\circ} \mathrm{C}$ and at a constant pressure of $25 \mathrm{MPa}$. 


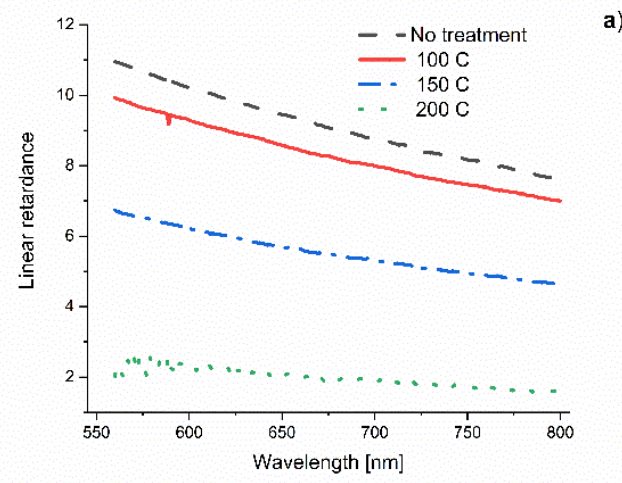

b)

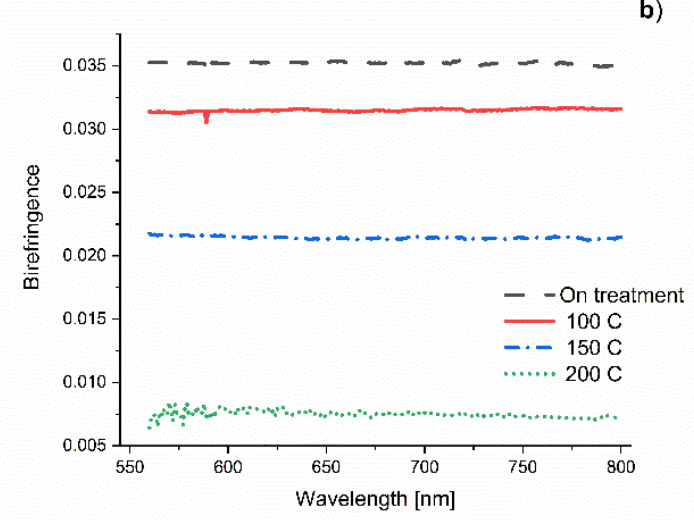

328 Fig 4. (a) Linear retardance and (b) birefringence of the reference and heat-treated 329 TO-CNF films as a function of the wavelength.

Microstructure of the TO-CNF films

332 Fig. 5 shows the TEM image of TO-CNFs and FESEM images of original TO-CNF and thermal treated TO-CNF films. TO-CNFs are flexible and elongated nanofibrils with an average length ranging from 172 to $958 \mathrm{~nm}$ and a width of $5 \pm 2 \mathrm{~nm}$. Both the reference (untreated) film and the films heat-treated at $100^{\circ} \mathrm{C}$ and $150^{\circ} \mathrm{C}$, 336 respectively, had a smooth and non-porous surface while small particles and holes

337 were observed on the surface of the film heat-treated at $200^{\circ} \mathrm{C}$. These micro- and nano-sized holes probably appeared as a result of the agglomeration of nano-sized

339 cavities between the cellulose molecular chains (Barbash et al. 2016). Moreover, 340 crevices appeared in the cross-section areas and became larger with higher 
341 temperature, indicating notable changes in the microstructure of the nanofibre 342 network.
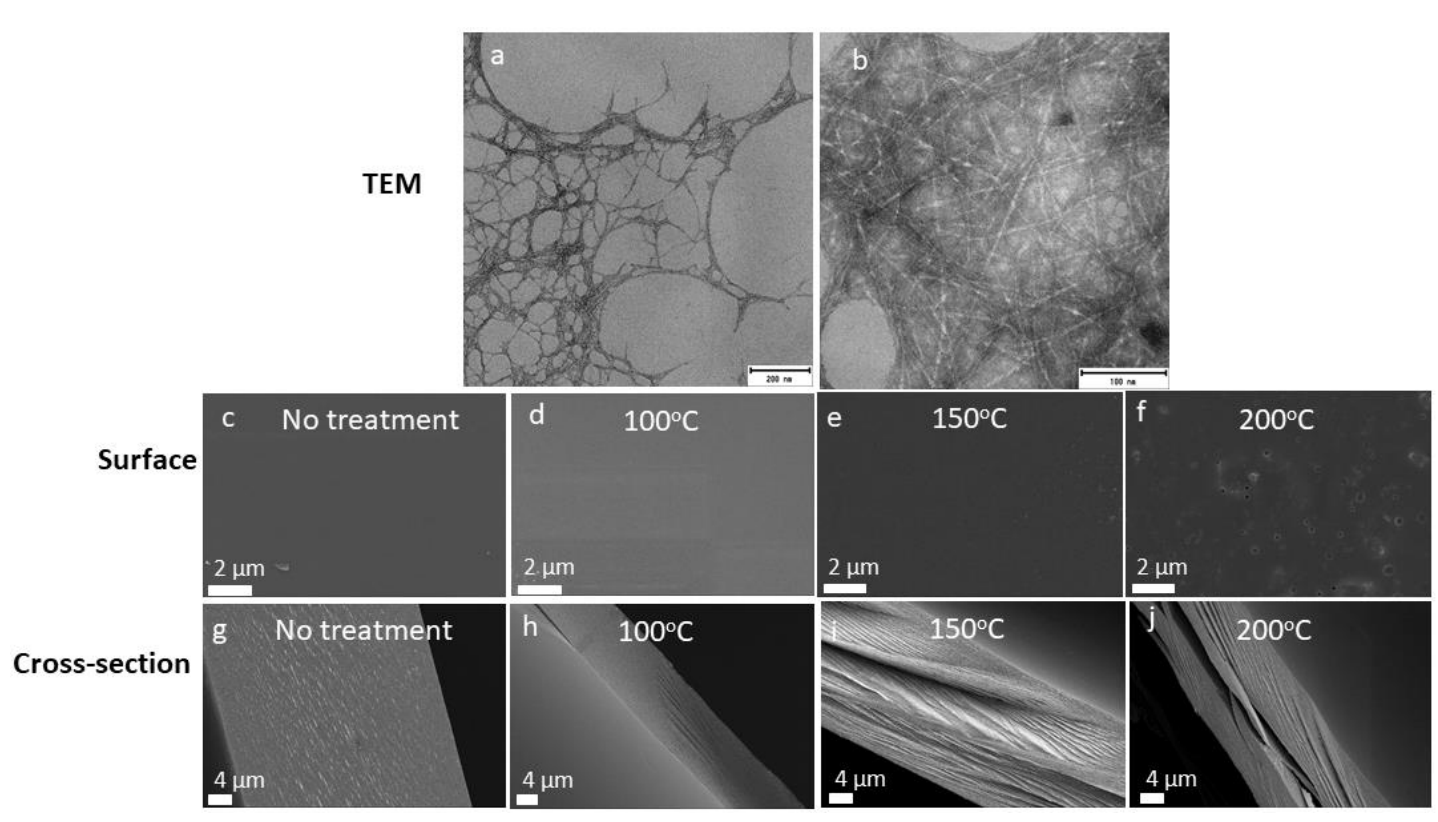

Fig. 5. TEM image of the reference TO-CNF and FESEM images of the surfaces $(\mathrm{a}-\mathrm{d})$ and cross-sectional areas $(\mathrm{e}-\mathrm{h})$ of the reference and heat-treated TO-CNF films.

\section{Crystalline structure of the thermally modified TO-CNF films}

Crystallinity has a significant effect on the physical, optical and mechanical properties of cellulose materials. Fig. 6 depicts the XRD patterns of the films treated at different temperatures in this study. All the films displayed typical cellulose I peaks, with the main $2 \theta$ diffraction angles at approximately 18.5 and $26^{\circ}$ ( $\mathrm{Co} \mathrm{K} \alpha$ radiation source) (Selkälä et al. 2016). The results indicated that the crystalline form (allomorph) of the cellulose remained unchanged during the heat treatment. For the films heat-treated at $100^{\circ} \mathrm{C}$ and $150^{\circ} \mathrm{C}$, their crystallinity indices $\left(C_{\mathrm{rI}}\right)$ decreased only slightly, indicating high crystalline ordering and good stability. However, for the film heat-treated at $200^{\circ} \mathrm{C}$, the $C_{\mathrm{rI}}$ decreased dramatically (from 58.4 to $45.6 \%$ ), 

structure of cellulose.

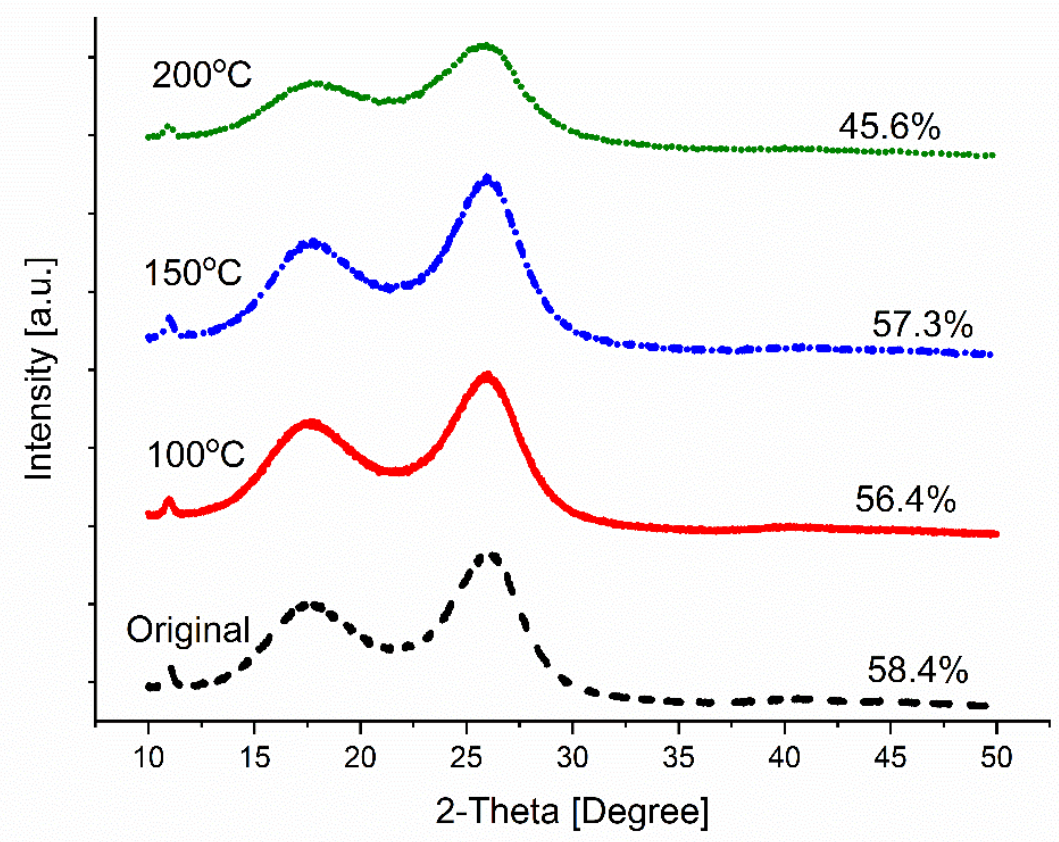

361 Fig. 6. X-ray diffractograms and crystallinity indices of the reference and heattreated TO-CNF films.

\section{Chemical analysis of the thermally modified TO-CNF films}

365 Fig. 7 shows the DRIFT spectra of the TO-CNF films in this study. All the DRIFT 366 spectra of the TO-CNF films showed the typical characteristic of cellulose and 367 similar chemical structures. The absorption peaks in the region between 3,350 and $3,740 \mathrm{~cm}^{-1}$ were $\mathrm{O}-\mathrm{H}$ stretching vibrations. The peaks at around $2,903 \mathrm{~cm}^{-1}$ were 369 associated with $\mathrm{C}-\mathrm{H}$ stretching vibrations. Notably, the peak at around $1,640 \mathrm{~cm}^{-1}$ 370 was the characteristic of the sodium carboxylate group originating from the

371 TEMPO-mediated oxidation. This peak shifted to a lower wavenumber value with

372 a higher heat treatment temperature, which was probably related to the formation

373 of intra- and interfibrillar hydrogen bonds promoted by the heat treatment (Abral et 374 al. 2020). Additionally, a new band at around $1,740 \mathrm{~cm}^{-1}$ appeared as the treatment 
375 temperature increased, which was probably ascribed to the carbonyl bonds in 376 chromophore groups formed during the heat treatment (Barbash et al. 2016).

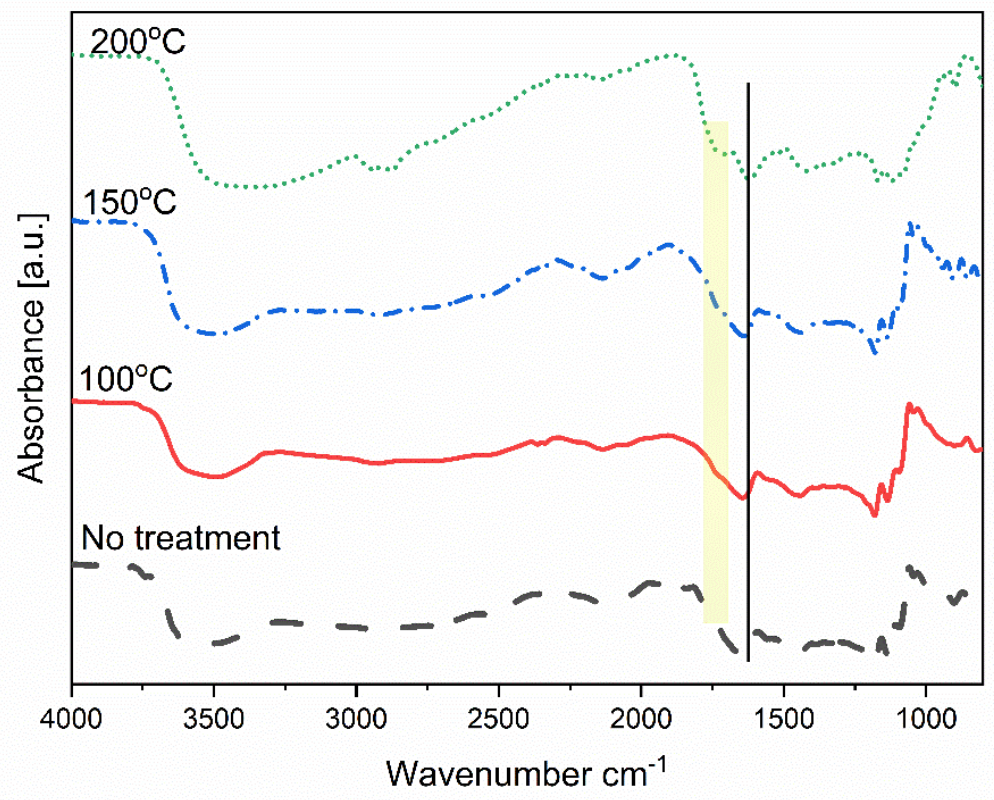

Fig. 7. DRIFT spectra of the reference and heat-treated TO-CNF films.

\section{Thermogravimetric analysis of the thermally modified TO-CNF films}

The results of the thermogravimetric analysis of the heat-treated films are shown in Fig. 8. All the films exhibited the typical three weight loss stages of nanocellulosic materials. The weights of all the samples that were heat-treated at temperatures under $200^{\circ} \mathrm{C}$ decreased slightly due to the evaporation of the absorbed water. As expected, this water loss decreased as a function of the heat treatment temperature because of the reduction of the residual water in the films. The second weight corresponding to the thermal degradation of the sodium carboxylates started at approximately $200^{\circ} \mathrm{C}$. Moreover, it can be noted that the film heat-treated at $200^{\circ} \mathrm{C}$ showed a higher thermal degradation point compared to the untreated film. Due to the thermal-oxidative decomposition of the char, a third weight loss was observed when the temperature was higher than $300^{\circ} \mathrm{C}$ (Zhao et al. 2013). Additionally, the 
amount of char at $1,000^{\circ} \mathrm{C}$ was $23.3 \%$ for the untreated film, $23 \%$ for the film heattreated at $100^{\circ} \mathrm{C}, 25.6 \%$ for the film heat-treated at $150^{\circ} \mathrm{C}$ and $30.2 \%$ for the film heat-treated at $200^{\circ} \mathrm{C}$. The higher amounts of char in the heat-treated films were reasonable because the weight loss or decomposition of the films already happened during the heat treatment, before the TG measurement. The temperatures at the

397 maximum weight losses of the reference film and the films heat-treated at $100^{\circ} \mathrm{C}$, $398150^{\circ} \mathrm{C}$ and $200^{\circ} \mathrm{C}$ were determined to be $241.2^{\circ} \mathrm{C}, 241.6^{\circ} \mathrm{C}, 241.9^{\circ} \mathrm{C}$ and $294.1^{\circ} \mathrm{C}$, 399 respectively. The higher thermal stability of the sample heat-treated at $200^{\circ} \mathrm{C}$ can 400 be related to its lower crystallinity, which produces a slow heat transfer ability 401 (Yildirim and Shaler 2017).

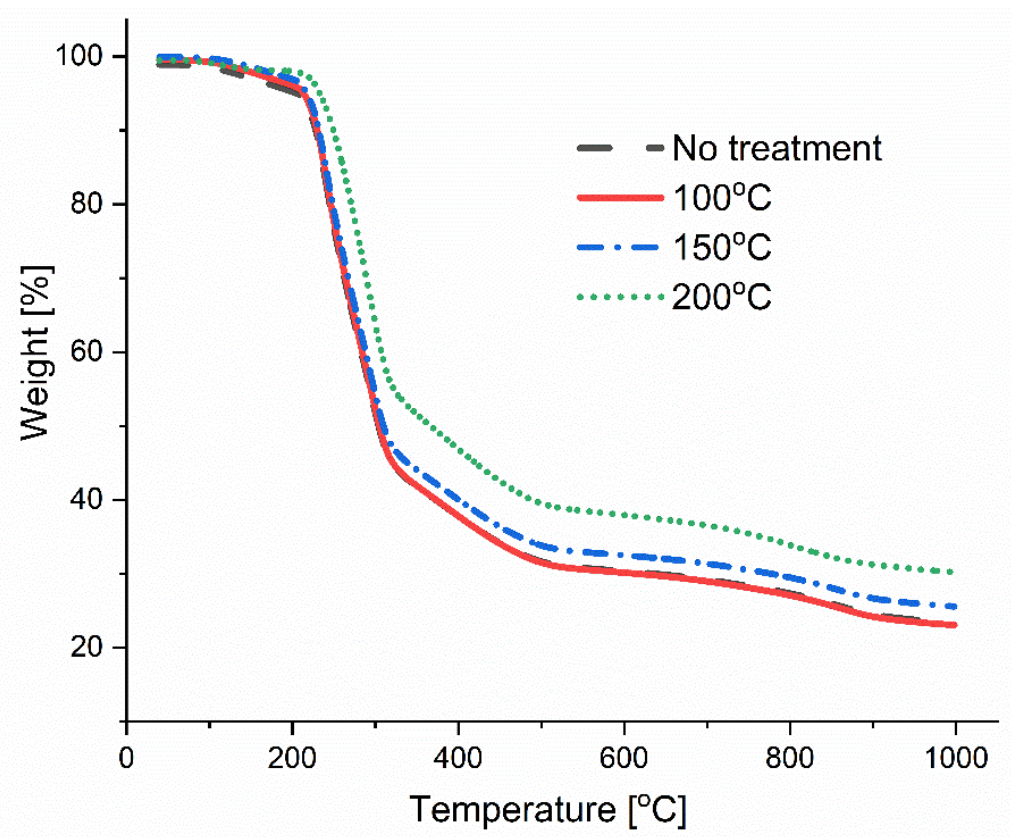

403 Fig. 8. Weight losses of the reference and heat-treated TO-CNF films.

\section{Mechanical properties of the thermally modified TO-CNF films}

406 The mechanical properties of the TO-CNF films in this study, as measured with the 407 universal testing machine, are presented in Fig. 9. All the TO-CNF films except the 408 film heat-treated at $200^{\circ} \mathrm{C}$ were easy to handle and flexible when bent. Both the 
409 tensile strength and the strain displayed a gradual decrease as a function of the heat

410 treatment temperature, already starting at $100^{\circ} \mathrm{C}$. However, the decreases in strength

411 and elongation were small only at $100^{\circ} \mathrm{C}$, when the tensile strength was still $>200$

$412 \mathrm{MPa}$ and the strain $>3.5 \%$. At the higher temperatures, the decreases in strength

413 and strain were notable.
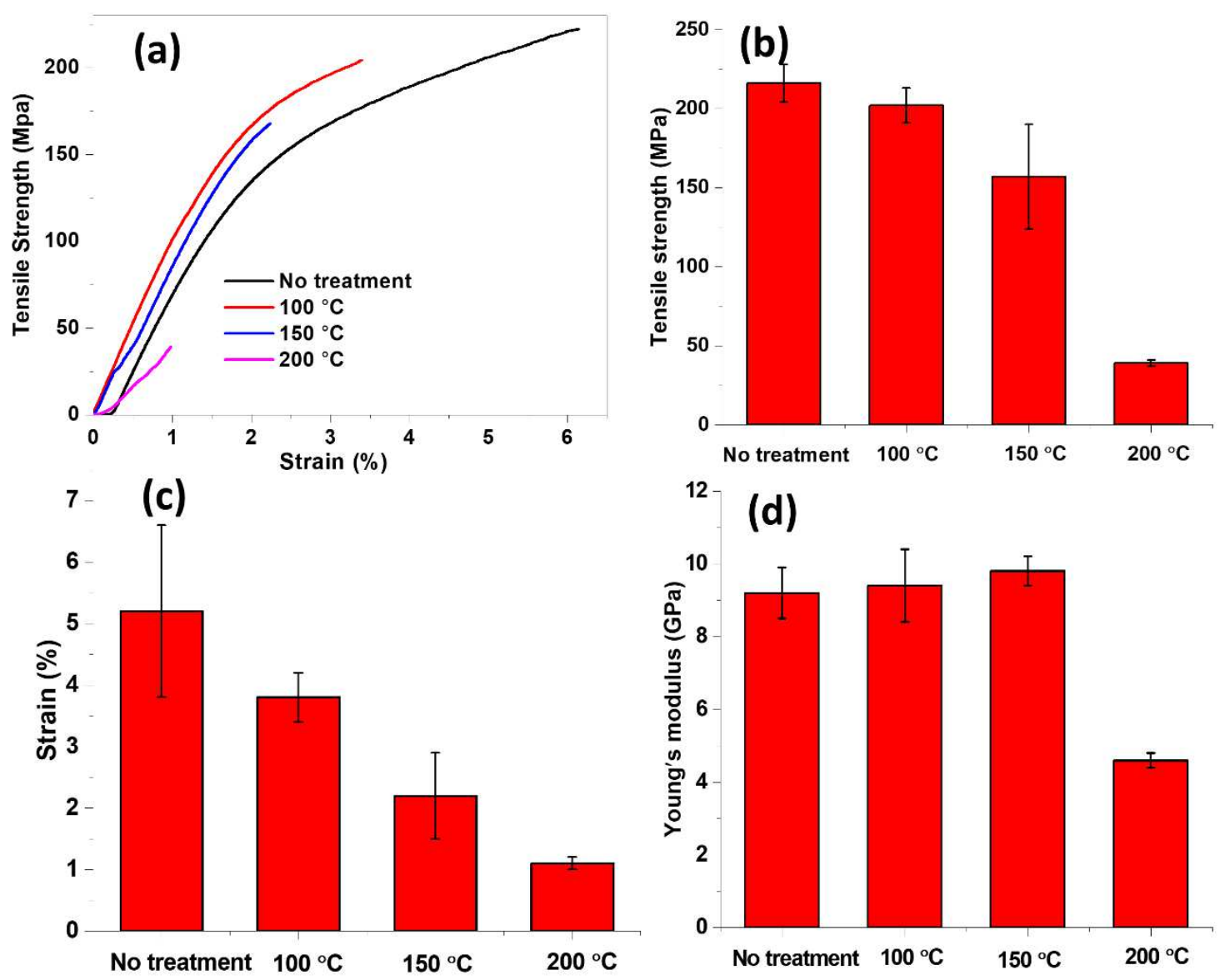

Fig. 9 (a) Typical tensile strength-strain curves and tensile strength (b), strain (c) and (d) Young's modulus of the TO-CNF films heat-treated at different

417 temperatures.

419 The Young's modulus, in turn, showed a slight increase as a function of the 420 treatment temperature (from 9.2 to $9.8 \mathrm{GPa}$ ) until $200^{\circ} \mathrm{C}$. This increase in stiffness 421 can be attributed to the formation of intra- and interfibrillar hydrogen and carbonyl 422 bonds due to the heat treatment (Fig. 7). The TO-CNF film heat-treated at $200^{\circ} \mathrm{C}$ 
423 had some small bubbles on its surface, and the film became more brittle and easier

424 to break. Thus, the mechanical properties of the film heat-treated at $200^{\circ} \mathrm{C}$ dropped

425 dramatically, and the tensile strength was only $39 \pm 2 \mathrm{MPa}$ ( $82 \%$ decrease compared

426 to the reference film), the strain was $1.1 \pm 0.1 \%$ (79\% decrease) and the Young's

427 modulus was $4.6 \pm 0.2 \mathrm{GPa}(50 \%$ decrease). The reduction of the mechanical

428 properties at the higher temperatures was mainly attributed to the decrease in the

429 degree of polymerisation of TO-CNF and to the destruction of the TO-CNF's

430 crystalline structure (Yang et al. 2019), which both decreased the mechanical

431 strength of the individual nanofibres.

\section{Conclusion}

435 The role of thermal stress in the molecular structure of cellulose and nanocellulose

436 is well known and reported in the literature. However, a basic understanding of the

437 optical characteristics of nanocellulose films at elevated temperatures is lacking

438 despite the fact that these are crucial properties in many applications. In the present

439 study, the effects of thermal treatment on the optical, structural and mechanical

440 properties of TO-CNF films were assessed.

441 The TO-CNF films were colourless at the low heat treatment temperatures $(<$

$442100^{\circ} \mathrm{C}$ ), but significant discolouration was noted at the higher temperatures (>

$443100^{\circ} \mathrm{C}$ ). The heat-treated films also showed a significant increase in refractive

444 index. This could have been due to the disappearance of the birefringence of CNF

445 when the temperature increased. The films heat-treated at high temperatures

446 presented lower weight loss in the TG analysis, especially the films heat-treated at

$447200^{\circ} \mathrm{C}$, but also had a significant decrease in crystallinity. Also, the heat treatment 
448 temperature $\left(>150^{\circ} \mathrm{C}\right)$ caused a notable decrease in the mechanical strength of the

449 TO-CNF films, and made the films brittle. These factors may limit the suitability

450 of the TO-CNF films for applications, and are presumably affected by the oxidised

451 groups in cellulose (i.e. $\mathrm{CO}$ and $\mathrm{COOH}$ ) formed during TEMPO treatment. Our

452 results provide a deeper understanding of the mechanisms of $\mathrm{CNF}$ restructuring

453 after the heat treatment process, and their impact on the optical and mechanical

454 properties of TO-CNF films.

455 Acknowledgments We gratefully acknowledge funding from Academy of Finland

456 ACNF projects (325276).

457 Ethics declarations

458 Human and animal rights This article does not contain any studies with human

459 participants or animals performed by any of the authors.

460 Conflict of interest The authors declare that they have no conflict of interest.

461 Availability of data and materials Yes.

\section{References}

Abitbol T, Rivkin A, Cao Y, Nevo Y, Abraham E, Ben-Shalom T, Lapidot S, Shoseyov O (2016)

465 Nanocellulose, a tiny fiber with huge applications. Current Opinion in Biotechnology.

466 https://doi.org/10.1016/j.copbio.2016.01.002

467 Abral H, Ariksa J, Mahardika M, Handayani D, Aminah I, Sandrawati N, Sugiarti E, Muslimin AN,

468 Rosanti SD (2020) Effect of heat treatment on thermal resistance, transparency and

469 antimicrobial activity of sonicated ginger cellulose film. Carbohydrate Polymers.

470 https://doi.org/10.1016/i.carbpol.2020.116287.

471 Agustin MB, Nakatsubo F,Yano H (2016) The thermal stability of nanocellulose and its acetates

472 with different degree of polymerization. Cellulose. https://doi.org/10.1007/s10570-015-0813-x

473 Ahn K, Zaccaron S, Zwirchmayr NS, Hettegger H, Hofinger A, Bacher M, Henniges U, Hosoya T,

474 Potthast A, Rosenau T (2019) Yellowing and brightness reversion of celluloses: $\mathrm{CO}$ or $\mathrm{COOH}$, who

475 is the culprit?. Cellulose. https://doi.org/10.1007/s10570-018-2200-x 
477 The effect of mechanochemical treatment of the cellulose on characteristics of nanocellulose

478 films. Nanoscale Res Lett. https://doi.org/10.1186/s11671-016-1632-1

479 Degushi S, Tsujii K, Horikoshi K (2006) Cooking cellulose in hot and compressed water. Chem

480 Communication. https://doi.org/10.1039/B605812D

481 Gan PG, Sam ST, Abdullah MF, Omar MF (2020) Thermal properties of nanocellulose-reinforced 482 composites: A review. J App. Polym Sci. https://doi.org/10.1002/app.48544

483 Isogai A, Saito T, Fukuzumi H (2010) TEMPO-oxidized cellulose nanofibers. Nanoscale.

484 https://doi.org/10.1039/CONR00583E

485 Jackson JD (1998) Classical electrodynamics. Willey, New York.

486 Kong L, Xu D, He Z, Wang F, Gu, S, Fan J, Pan X, Dai X, Dong X, Liu B, L, Y (2019) Nanocellulose-

487 reinforced polyurethane for waterborne wood coating. Molecules.

488 https://doi.org/10.3390/molecules24173151

489 Liimatainen H, Sirviö J, Haapala A, Hormi O, Niinimäki J (2011) Characterization of highly

490 accessible cellulose microfibers generated by wet stirred media milling. Carbohydrate Polymers.

491 https://doi.org/10.1016/j.carbpol.2010.11.007.

492 Macleod HA (2021) Thin-film optical filters. CRC Press, Boca Raton.

493 Manaf MEA, Nitta KH, Yamgusci M (2016) Mechanical properties of plasticized cellulose ester

494 films at room and high temperatures. ARPN Journal of Engineering and Applied Science.

495 Matsuo M, Umemura K, Kawai S (2012) Kinetic analysis of color changes in cellulose during heat 496 treatment. J Wood Sci.. https://doi.org/10.1007/s10086-011-1235-5

497 Nanocellulose market (2020), Report code CH3320. https://www.markets

498 andmarkets.com/Market-Reports/nano-cellulose-market-56392090.html (accessed 12 May

499 2021).

500 Nilsson PO (1968) Determination of optical constants from intensity measurements at normal 501 incidence. Appl Opt. https://doi.org/10.1364/AO.7.000435

502 Niskanen I, Forsberg V, Zakrisson D, Reza S, Hummelgård M, Andres B, Fedorov I, Suopajärvi T, 503 Liimatainen $\mathrm{H}$, Thungström G (2019a). Determination of nanoparticle size using Rayleigh 504 approximation and Mie theory. Chemical Engineering Science.

505 https://doi.org/10.1016/i.ces.2019.02.020

506 Niskanen I, Heikkinen J, Mikkonen J, Harju A, Heräjärvi H, Venäläinen M, Peiponen KE (2012). 507 Detection of the effective refractive index of thermally modified scots pine by immersion liquid 508 method. J Wood Sci. https://doi.org/10.1007/s10086-011-1222-x

509 Niskanen I, Räty J, Soetedjo H, Hibino K, Oohashi H, Heikkilä R, Matsuda K, Otani Y (2020) 510 Measurement of the degree of polarisation of thermally modified Scots pine using a Stokes 511 imaging polarimeter. Opt Rev. 178-182. https://doi.org/10.1007/s10043-019-00572-w

512 Niskanen I, Suopajärvi T, Liimatainen H, Fabritius T, Thungström G (2019b) Determining complex 513 refractive index of cellulose nanocrystals by combination of Beer-Lambert and immersion 514 matching methods. Journal of Quantitative Spectroscopy \& Radiative Transfer.

$515 \quad$ https://doi.org/10.1016/i.jasrt.2019.06.023

516 Orellana JL, Wichhart D, Kitchens CL (2018) Mechanical and optical properties of polylactic acid

517 films containing surfactant-modified cellulose nanocrystals. Journal of Nanomaterials.

518 https://doi.org/10.1155/2018/7124260 
519 Pakharenko V, Sameni J, Konar S, Pervaiz M, Yang W, Tjong J, Oksman K, Sain M (2021) Cellulose 520 nanofiber thin-films as transparent and durable flexible substrates for electronic devices.

521 Materials \& Design.https://doi.org/10.1016/i.matdes.2020.109274

522 Reid MS, Villalobos M, Cranston ED (2016) Cellulose nanocrystal interactions probed by thin film 523 swelling to predict dispersibility. Nanoscale. https://doi.org/10.1039/C6NR01737A

524 Rubentheren V, Ward TA, Chee CY, Nair P, Salami E (2016) Effects of heat treatment on chitosan 525 nanocomposite film reinforced with nanocrystalline cellulose and tannic acid. Carbohydrate 526 Polymers.https://doi.org/10.1016/i.carbpol.2015.12.068

527 Selkälä T, Sirviö J A, Lorite, G S, Liimatainen H (2016) Anionically stabilized cellulose nanofibrils

528 through succinylation pretreatment in urea-lithium chloride deep eutectic solvent.

529 Chemsuschem. https://doi.org/10.1002/cssc.201600903

530 Smith $\mathrm{MH}$ (2002) Optimization of a dual-rotating-retarder Mueller matrix polarimeter. Appl Opt.

531 https://doi.org/10.1364/AO.41.002488

532 Sun X, Wu Q, Zhang X, Ren S, Lei T, Li W, Xu G, Zhang Q (2018) Nanocellulose films with combined 533 cellulose nanofibers and nanocrystals: tailored thermal, optical and mechanical properties.

534 Cellulose. https://doi.org/10.1007/s10570-017-1627-9

535 Uetani K, Koga H, Nogi M (2019) Estimation of the intrinsic birefringence of cellulose using

536 bacterial cellulose nanofiber films. ACS Macro Letters.

537 https://doi.org/10.1021/acsmacrolett.9b00024

538 Vardanyan V, Galstian T, Riedl B (2015) Effect of addition of cellulose nanocrystals to wood 539 coatings on color changes and surface roughness due to accelerated weathering. J Coat Technol 540 Res. https://doi.org/10.1007/s11998-014-9634-3

541 Wang Q, Yao Q, Liu J, Sun J, Zhu Q, Chen H (2019). Processing nanocellulose to bulk materials: a 542 review. Cellulose. https://doi.org/10.1007/s10570-019-02642-3

543 Wu Q, Meng Y, Concha K, Wang S, Li Y, Ma L, Fu S (2013) Influence of temperature and humidity 544 on nano-mechanical properties of cellulose nanocrystal films made from switchgrass and cotton. 545 Industrial Crops and Products. https://doi.org/10.1016/i.indcrop.2013.03.032

546 Yang W, Gao Y, Zuo C, Deng Y, Dai H (2019) Thermally-induced cellulose nanofibril films with 547 near-complete ultraviolet-blocking and improved water resistance. Carbohydrate polymers. 548 https://doi.org/10.1016/i.carbpol.2019.115050.

549 Yildirim N, Shaler SA (2017) Study on thermal and nanomechanical performance of cellulose 550 nanomaterials (CNs). Materials. https://doi.org/10.3390/ma10070718

551 Zhao J, Zhang W, Zhang X, Zhang X, Lu C, Deng Y (2013) Extraction of cellulose nanofibrils from 552 dry softwood pulp using high shear homogenization. Carbohydrate Polymers.

553 https://doi.org/10.1016/j.carbpol.2013.05.050

554 Zhu JY, Sabo R, Luo X (2011) Integrated production of nano-fibrillated cellulose and cellulosic 555 biofuel (ethanol) by enzymatic fractionation of wood fibers. Green

556 Chemistry.https://doi.org/10.1039/C1GC15103G

557 Zlenko DV, Nikolsky SN, Vedenkin AS, Politenkova GG, Skoblin AA., Melnikov VP, Michaleva MM, 558 Stovbun SV (2019) Twisting of fibers balancing the gel' ${ }^{-}$sol transition in cellulose aqueous 559 suspensions. Polymers. https://doi.org/10.3390/polym11050873 


\section{Supplementary Files}

This is a list of supplementary files associated with this preprint. Click to download.

- Graphicalabstract.pdf

- datafigures.7z 